\title{
Preliminary Investigation for Feasibility of Wave Energy Converters and the Surrounding Sea as Test-site for Marine Equipment
}

\author{
Jin-Yeong Park ${ }^{1}$, Hyuk Baek $\oplus^{2}$, Hyungwon Shim $\oplus^{3}$ and Jong-Su Choi $\oplus^{4}$ \\ ${ }^{1}$ Principal researcher, Ocean System Engineering Research Division, KRISO, Daejeon, Republic of Korea \\ ${ }^{2}$ Senior engineer, Ocean System Engineering Research Division, KRISO, Daejeon, Republic of Korea \\ ${ }^{3}$ Principal researcher, Alternative Fuels and Power System Research Center, KRISO, Daejeon, Republic of Korea \\ ${ }^{4}$ Principal researcher, Marine Renewable Energy Research Division, KRISO, Daejeon, Republic of Korea
}

KEY WORDS: Oscillating water column, Multi-beam echo sounder, Single-beam scanning sonar, Test-site, Functional modelling(IDEF0)

\begin{abstract}
Of late, demand for test sites for marine equipment such as ASV, AUV, ROV, and various underwater sensors is increasing. The authors have focused on an oscillating water column (OWC), which is being constructed near Chagwido Island Jeju, as one of the test-sites. The main objective of the OWC is to produce wave energy and develop technologies. It has been built in the sea approximately $1 \mathrm{~km}$ off the coast. It has berth accommodation and some rooms that can be used as laboratories. To investigate the feasibility of its usage as a test site for marine equipment, we acquired bathymetric data around the OWC by using a multi-beam echo sounder and a single-beam scanning sonar. The accessibility of the OWC from nearby ports and the use of support vessels or ships were also investigated. 3D point cloud data from the multi-beam echo sounder and $2 D$ acoustic images from the scanning sonar are expected to be used as references for identifying changes over time. In addition, through these experiments, we derived a procedure to use this facility as a test site by using the IDEFO functional modelling method. Based on this preliminary investigation and previously reported examples, we determined the general conditions and preferences for evaluating the performance of various marine equipment heuristically. Finally, we developed five applications that were derived from this investigation.
\end{abstract}

\section{Introduction}

Of late, demand for sites and platforms to test the performance of marine equipment and underwater and surface robots during the development process has been increasing in South Korea. The Korea Research Institute of Ships and Ocean Engineering(KRISO) has performed unit performance and overall performance tests at the Jangmok wharf in Geoje-si, where the South Sea Research Institute (SSRI) of the Korea Institute of Ocean Science and Technology (KIOST) is located, and engaged in the development of a deep-sea remotely operated vehicle (ROV), Hemire, and an autonomous underwater vehicle (AUV), ISiMI 100 (Baek et al., 2008; Jun et al., 2009). Tests for the location estimation performance of underwater vehicles were also performed in the inland environment of Jangseongho in Jeollanam-do (Choi et al., 2019a). Defense industry companies carried out experiments for motion characteristic modeling of AUVs for underwater reconnaissance and hydrodynamic coefficient adjustment and experiments for performance verification in the real sea at the South Sea Research Institute wharf (Park et al., 2015; Lee et al., 2015). Other experiments, mostly for the development performance verification of individual maritime unmanned vehicles, are being carried out in the coastal sea of the Jinhae Naval Academy in Gyeongsangnam-do, the Korea Maritime and Ocean University wharf in Busan, the coastal sea of Pohang, Gyeongcheonho in Mungyeong, and Bangdongho in Daejeon (Jeollabuk-do, 2019). The sites mentioned above need to separately provide facilities required for test preparation, including space for maintenance and repair of test equipment on land including wharf facilities. The need and demand for performance verification in real sea environments is also increasing with the increasing levels of technology and equipment being developed.

The Ministry of Maritime Affairs and Fisheries is building a 5 MW

Received 19 February 2020, revised 5 September 2020, accepted 15 September 2020

Corresponding author Jin-Yeong Park: +82-42-866-3835, jinyeong96@kriso.re.kr

It is a recommended paper from the Proceedings of the 2019 Fall Conference of the Korea Marine Robot Technology (KMRTS), hich is one of the divisions of the Korean Society of Ocean Engineers (KSOE).

(c) 2020, The Korean Society of Ocean Engineers

This is an open access article distributed under the terms of the creative commons attribution non-c

ommercial license (http://creativecommons.org/licenses/by-nc/4.0) which permits unrestricted non-commercial use, distribution, and reproduction in any medium, provided the original work is properly cited. 
test infrastructure in the sea near Chagwi Island of Jeju-do for the distribution and expansion of wave power generation and promotion of related domestic industries. The final goal of the infrastructure is to allow performance evaluation, installation and recovery technique verification, operating technique optimization, and system stability tests of wave power generators. Various performance tests related to wave power generation are expected to be performed after the completion of the infrastructure (Choi et al., 2019b). Among those wave power generators, the oscillating water column (OWC) wave power generator (or wave power test-bed) constructed in the sea is expected to provide test environments for a variety of maritime equipment in addition to wave power generation-related technologies, as facilities for supplying electricity and relaying communication can be additionally installed and space for maintenance and operation of mid and small equipment can be secured.

The Oceanic Platform of the Canary Islands (PLOCAN), which is representative of similar overseas facilities, is currently used based on the technical science services of multipurpose maritime equipment. It has ROVs and underwater gliders and has secured approximately 23 $\mathrm{km}^{2}$ of sea as a test site. Using PLOCAN, tests are being performed on a variety of equipment (González et al., 2015). This includes application to ocean surveillance technology development by using an autonomous surface vehicle(ASV) equipped with a passive acoustic signature detector (ASD) in the Protecting European Seas and Borders through the Intelligent Use of Surveillance (PERSEUS), carried out with support from the European Union (Real-Arce et al., 2015). This study describes preliminary research on the investigation of the suitability of OWC as infrastructure in maritime equipment tests. The preliminary research is to procure terrain information for the underwater lower structure of a wave power test-bed and the surrounding seabed environment. To do so, multi-beam echo sounder (MBES) and single-beam scanning sonar (hereafter, the scanning sonar) data are to be acquired using a vessel. In operation, the MBES is mounted on the bottom of a vessel and the scanning sonar is launched and installed on the seabed. The former acquires three-dimensional point clouds, whereas the latter obtains two-dimensional images. The above two types of equipment are typical seabed mapping sensors. First, the seabed space information around the OWC is acquired to be taken into consideration when selecting target test equipment and establishing test plans. In addition, the case where maritime equipment performance tests are carried out using small vessels is postulated to derive a model based on the integrated computer-aided manufacturing (ICAM) definition(IDEF0) for function modeling, and refer to the model for the identification of the required conditions, criteria, resources, etc. Jangmok No. 1 belonging to the SSRI, KIOST was used in the tests. The vessel is equipped with the necessary equipment including a MBES for this experiment. The measurement data of the MBES were processed along with the location and attitude data of the vessel to extract and store three-dimensional points with respect to the earth-fixed coordinate system. The computers for the scanning sonar operation and its data storage needed to be prepared separately. The tests were carried out for two days in April 2019.

The wave power test-bed and environment, including location characteristics and building specifications, are introduced in Chapter 2. Chapter 3 describes experiments using the MBES and scanning sonar and includes experiment goals to demonstrate the experimental results for each sensor and the results of establishing the experiment procedure using an IDEF0 function modeling method. Suitability analysis results and characteristics of the experiment environment of the OWC and derived, and applicable fields/businesses are described in Chapter 4.

\section{Wave Power Test-Bed Site}

\subsection{Wave Power Test-Bed}

The wave power test-bed is being constructed in the sea near Chagwi Island of Jeju-do. The surrounding sea has high wave energy density and light maritime traffic, and includes medium ports such as the Hallim port and Aewol port. The appropriateness of the site was verified through seabed exploration (Kim et al., 2017). The wave power test-bed site consists of total five berths, with Berth 1 being the OWC wave power generator. Fig. 1 shows the conceptual diagram. The offshore substation installed on the sea is the OWC. Fig. 2 shows the size using the upper structure of the OWC exposed above the sea surface (left) and three-dimensional modeling (right). The height of the OWC from the seabed is $27.5 \mathrm{~m}$, and the tide-dependent height of

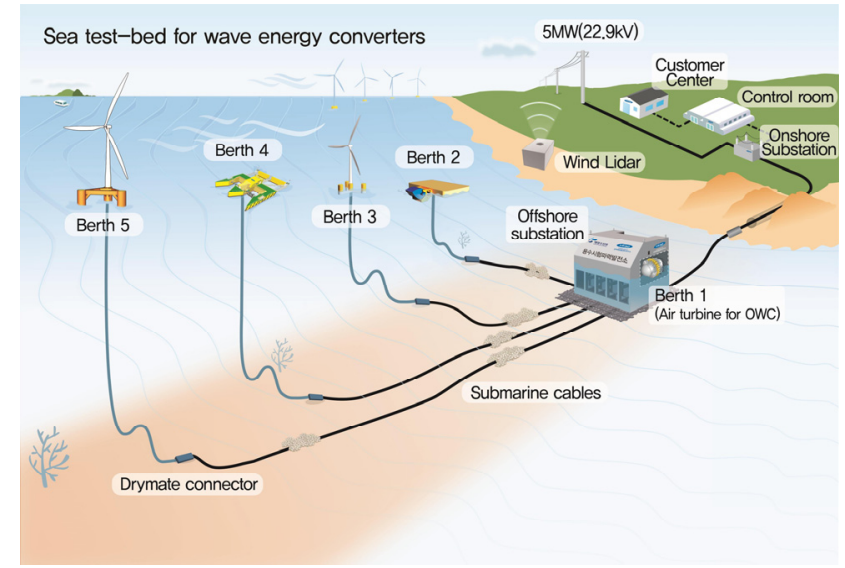

Fig. 1 Conceptual art of arrangement for open sea test site for wave energy converter
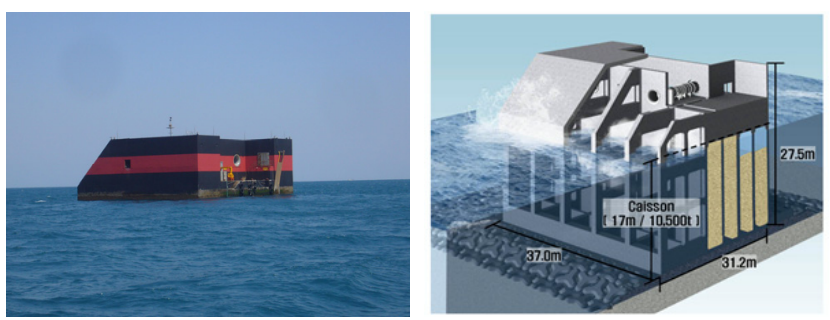

Fig. 2 Structure of the OWC (Oscillating Water Column) exposed above the sea surface (left). Perspective view of $3 \mathrm{D}$ modelling of the OWC structure showing its size (right) 


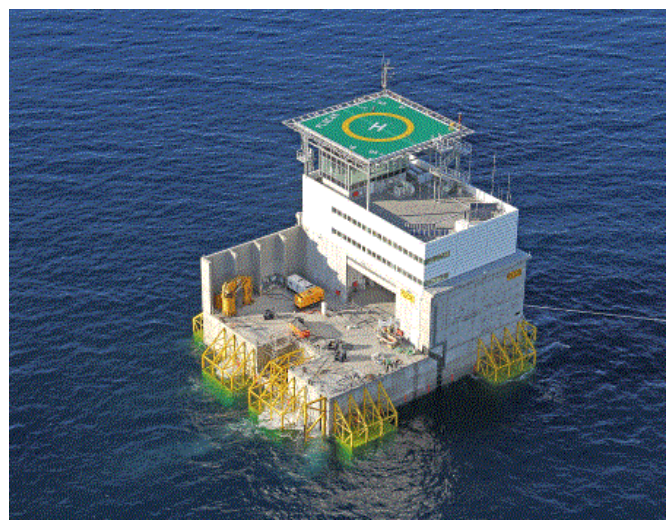

Fig. 3 PLOCAN platform (PLOCAN, 2020)

the protruding portion above the sea surface is approximately $15 \mathrm{~m}$. The length and width are $37.0 \mathrm{~m}$ and $31.2 \mathrm{~m}$, respectively. The seabed terrain includes bedrock expected to have little feature change. The depth of water ranges from $10 \mathrm{~m}$ to $60 \mathrm{~m}$. The turbidity is relatively lower than the West/South Sea. Power cables are laid here after construction. Fig. 3 shows the PLOCAN platform. PLOCAN is used as a real sea test-bed for ocean energy and maritime equipment similar to the OWC and is separated from the coast by $1.85 \mathrm{~km}$. It is constructed in a region with a water depth of $30.5 \mathrm{~m}$. The total area used is 5000 $\mathrm{m}^{2}$, and the length and width are $33 \mathrm{~m}$ and $38 \mathrm{~m}$, respectively. It has a helicopter deck, gantry crane, office space, drinking water purifier, and launch and recovery system (LARS). It includes a Seabotix ROV and a Slocum glider (PLOCAN, 2019).

\subsection{Surrounding Environment}

Nearby ports include Yongsu-ri, Hallim, and Aewol. The Yongsu-ri port is the closest, and the Aewol port is the farthest. Small ports exist between the three ports. A port limits the scale of the support vessel using it, which requires space for storage, management, repair, and must facilitate loading and unloading of sensors and equipment to be tested. The ports mentioned above do not meet these requirements. Weather and sea state are important elements of offshore experiments. Thus, time and space in preparation for these elements need to be secured.

The sea west of Jeju-do, on which wave power test facilities are built, along with the islands Dokdo, Ulleungdo, and Hongdo, is known as an area with high wave energy in South Korea (Ryu et al., 2011). Wave energy data for the power generation performance evaluation of a wave power generator is collated (Park et al., 2019), and numerical wave models are being developed. A database for wind direction and wind velocity information using wind light detection and ranging (LiDar) is also constructed.

\section{MBES and Scanning Sonar Experiment}

There are two main objectives of this experiment.

- Collect information on the seabed terrain around the OWC, and

- Collect fundamental information for establishing a performance test procedure around the OWC using a small vessel.

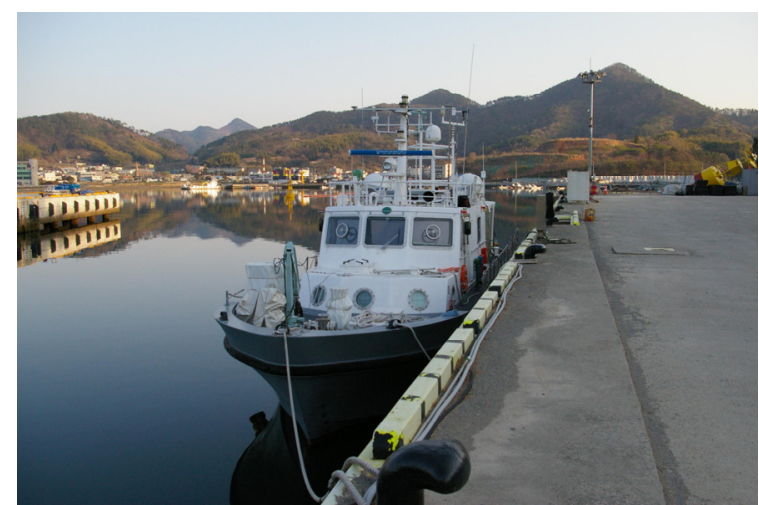

Fig. 4 Research vessel Jangmok No. 1

Once the information on the seabed terrain around the OWC is collected, changes caused by the construction of the OWC can be verified and are expected to be used as a reference in tracking seabed environment changes caused by the OWC or similar structures after a certain amount of time elapses. Moreover, a procedure for the case in which performance tests of maritime equipment are carried out around the OWC using a small vessel, is to be established through this experiment.

The support vessel used in this experiment is Jangmok No. 1 of the SSRI of KIOST. It is a small research vessel for coastal exploration and observation activities such as domestic coastal seabed geology, underwater resource exploration, and terrestrial magnetism investigation. Its full length is $24.22 \mathrm{~m}$, international gross tonnage is $41 \mathrm{t}$, and sea speed is $13 \mathrm{kn}(6.7 \mathrm{~m} / \mathrm{s})$. A maximum of 15 people (4 crew members and 11 researchers) can be onboard (KIOST, 2019a). Fig. 4 shows Jangmok No. 1. Typical sensors installed on it include conductivity temperature depth (CTD), sub-bottom profiler (SBP), acoustic Doppler current profiler (ADCP), EA400, and MBES.

\subsection{Multi-Beam Echo Sounder}

The MBES installed on the bottom of Jangmok No. 1 is EM3002 and is provided by Kongsberg (Table 1). The data were acquired by turning the OWC around. A separate calibration process for the MBES prior to data acquisition was not undertaken due to limitations including budget and test schedule.

Fig. 5 shows the MBES results before OWC construction (a), and the MBES results acquired around the OWC along the submarine cables in this experiment (b). Although accurate comparisons of

Table 1 Specifications of EM3002 Kongsberg

\begin{tabular}{ll}
\hline \multicolumn{1}{c}{ Item } & \multicolumn{1}{c}{ Description } \\
\hline Frequencies & 293,300, and $307 \mathrm{kHz}$ \\
Number of sounding per ping: & \\
Single sonar head & Max. 254 \\
Dual sonar head & Max. 508 \\
Max. ping rate & $40 \mathrm{~Hz}$ \\
Pulse length & $150 \mu \mathrm{s}$ \\
Depth resolution & $1 \mathrm{~cm}$ \\
\hline
\end{tabular}




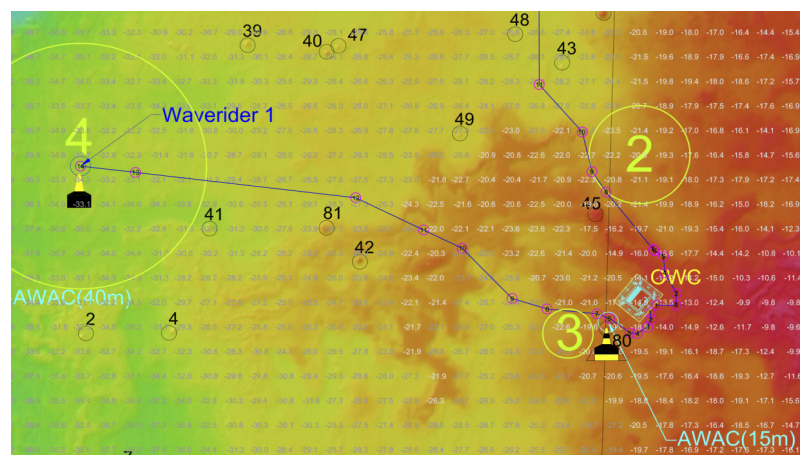

(a) Arrangement plan of the OWC and submarine cables

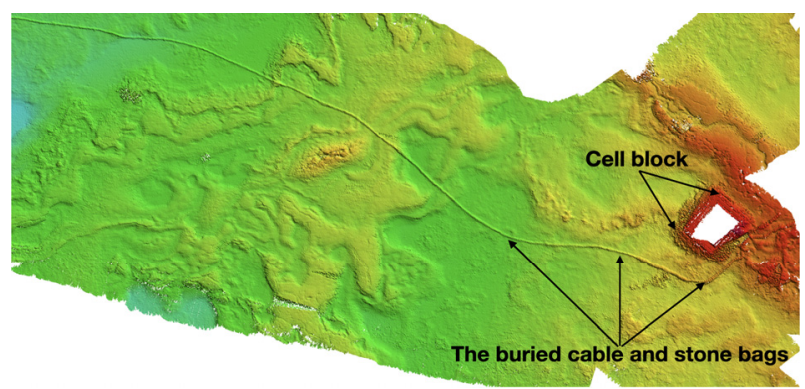

(b) Actual arrangement of the OWC and submarine cables

Fig. 5 A before-and-after comparison of the bathymetric images

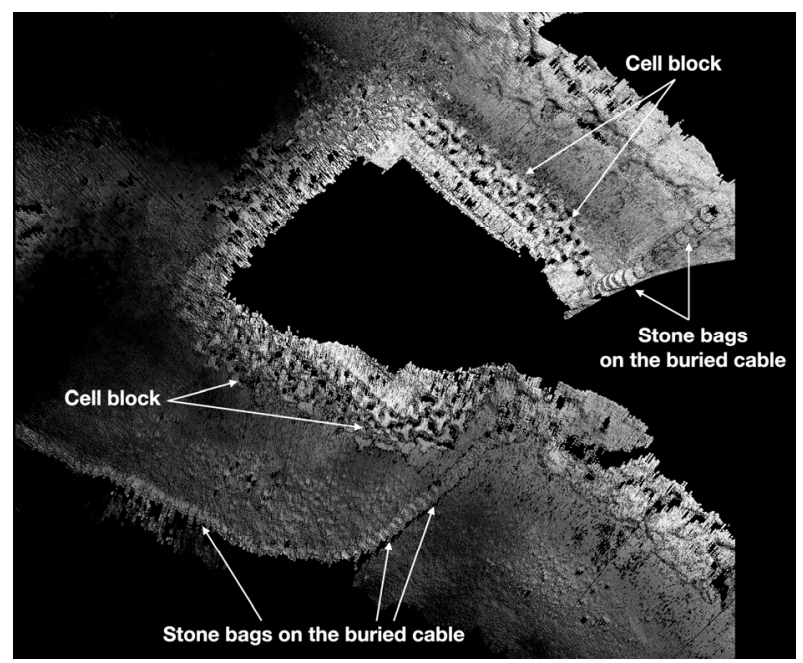

Fig. 6 Back-scattering data image

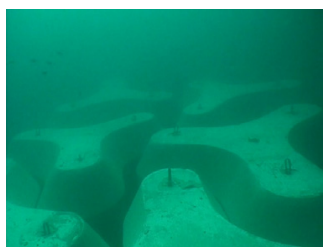

(a) Cell blocks around submerged structure of the OWC

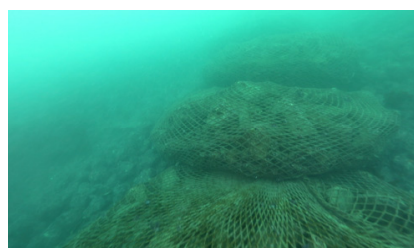

(b) stone bags covering the underwater cable
Fig. 7 Cell blocks and stone bags taken by optical camera

coordinates are difficult to make because calibration before acquisition and postprocessing (such as tidal correction) after acquisition is not performed, submarine cable and cell blocks supporting the ground bed of the OWC can be verified. Fig. 6 is a back-scattering data image. Fibrous stone bags stacked on top of each other to protect the submarine cables and cell blocks around the lower structure of the OWC can be observed more clearly. Fig. 7 shows the cell blocks and stone bags photographed by an imaging camera.

\subsection{Single-Beam Scanning Sonar}

The scanning sonar used in this study is the 1171 high resolution scanning sonar model provided by Kongsberg Mesotech. Its detailed specifications are listed in Table 2. It is operable up to a maximum depth of $3000 \mathrm{~m}$ and uses a frequency of $675 \mathrm{kHz}$. It requires a tripod to independently acquire seabed images and can acquire circular

Table 2 Specifications of 1171 scanning sonar

\begin{tabular}{ll}
\hline \multicolumn{1}{c}{ Item } & \multicolumn{1}{c}{ Description } \\
\hline Depth rating & $3,000 \mathrm{~m}$ \\
Frequency & $675 \mathrm{kHz}$ \\
Range & $0.5-100 \mathrm{~m}$ \\
Range resolution & $\geq 19 \mathrm{~mm}$ \\
Scan speed & $11 \mathrm{~s} / 360^{\circ} @ 10 \mathrm{~m} \mathrm{\&} 1.8^{\circ}$ step \\
Scan width & $36 \mathrm{~s} / 360^{\circ} @ 100 \mathrm{~m} \mathrm{\&} 1.8^{\circ}$ step \\
Step size & $360^{\circ}$ continuous \\
Pulse length & $\geq 0.225^{\circ}$ \\
\hline
\end{tabular}

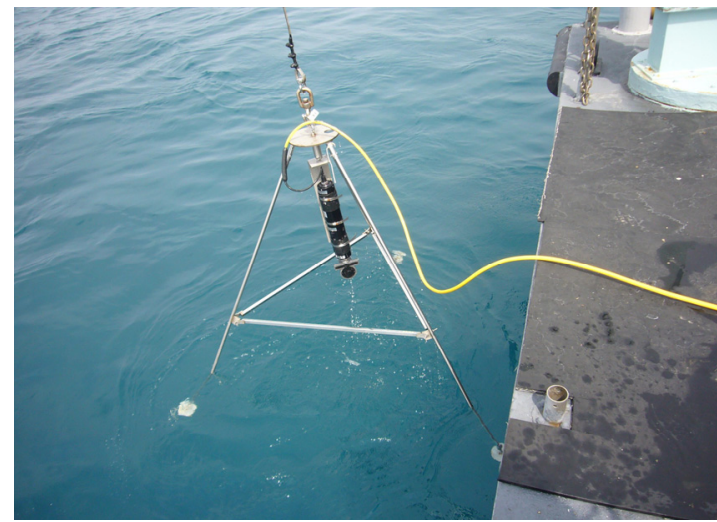

Fig. 8 Launch of 1171 scanning sonar from Jangmok No.1

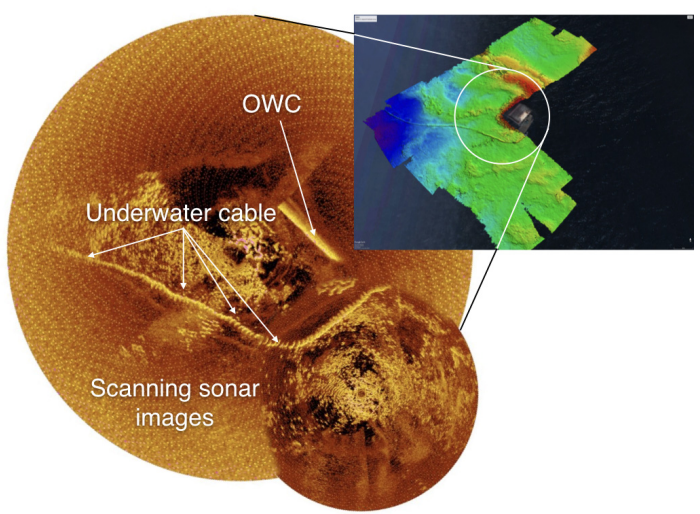

Fig. 9 Mosaicked images of 1171 scanning sonar 
images of a scanning radius that is set in a scanning sonar operating program. The maximum scanning radius is $100 \mathrm{~m}$. The scanning sonar can be operated with a minimum rotation angle of $0.225^{\circ}$. Fig. 8 depicts a scene in which the scanning sonar installed on a tripod is launched from the stern of Jangmok No. 1. Divers are normally required to stably install sensors on the seabed protected against the tidal current, but divers could not be recruited in this work due to the schedule and state of the sea. As a result, the vessel, sensor, and tripod were pushed by the tidal current. The tripod was pushed or fell from time to time during the measurement. Therefore, the sensor only briefly could be stable position while scanning.

Divers should be recruited for more precise observation in the future. Consequently, images at two points were acquired, and the mosaicked results are shown in Fig. 9. The images have a higher resolution than the MBES images and the stone bags for burying and protecting the submarine cables can be identified.

\subsection{Maritime Equipment Performance Test Procedure Establishment}

A test performed in an actual sea incurs high costs. The overall operation period and all items required for the operation are specified in a contract. If an operations company does not have a standardized procedure, the test is even more complex and difficult to perform. It is quite difficult for the company to come up with a standard (Rocha and De Tomi, 2015).

The IDEF0 modelling technique is a function modeling method that was developed as part of the ICAM project of the US Air Force in the 1970s, and can model any system in which people, hardware, and software are all connected. This method is used to systematically manage and utilize a target system to be analyzed or designed by defining functions, the information required of the system, and the order between the functions (the National Institute of Standards and Technology, 1993). Particularly, it has a feature of easily modeling a complex system as it supports a hierarchical model structure (Kim, 2005). Study cases that established complex work procedures

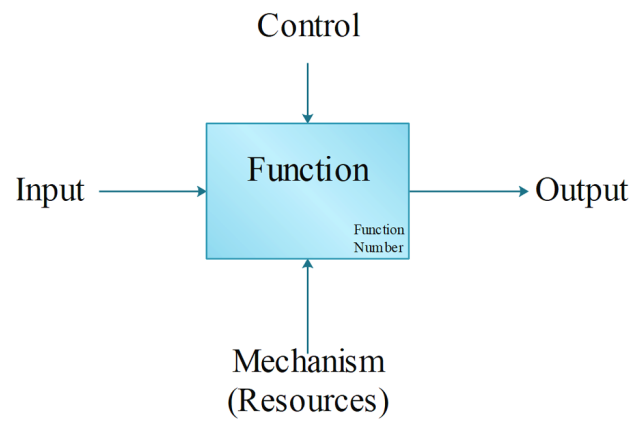

Fig. 10 IDEF0 box format

using equipment on the sea using the IDEF0 function modeling method include the case applied to the safety inspection of an offshore structure (Rocha and De Tomi, 2015), and the case applied to underwater unidentified object identification using a small ROV (Baek et al., 2019).

This section establishes the procedure based on the information obtained from the MBES and scanning sonar test site of Chapter 3 and is modelled by IDEF0. Fig. 10 shows the basic diagram of IDEF0. A function is expressed in a box format, and functions performed by people, machines, or computers are expressed as descriptions about what happens and under what conditions. Each function box is connected by input, control, output mechanism (ICOM), and a lower level can be decomposed into subfunctions in more detail.

Fig. 11 is assigned code A- 0 as an activity of the highest level. The function of A- 0 defines the provision of a multi-purpose technical scientific service as the function of the OWC, and its input/output, control, and mechanism are illustrated. Multi-purpose technical scientific service is a function for acquiring data required to evaluate the performance and precision of the sensor. Real-time surface environment data of an auto weather system (AWS) and data of the underwater environment (current direction, current velocity, sea level, etc.) installed on the OWC are input values. A final report with output values is generated by control. Control elements are defined as

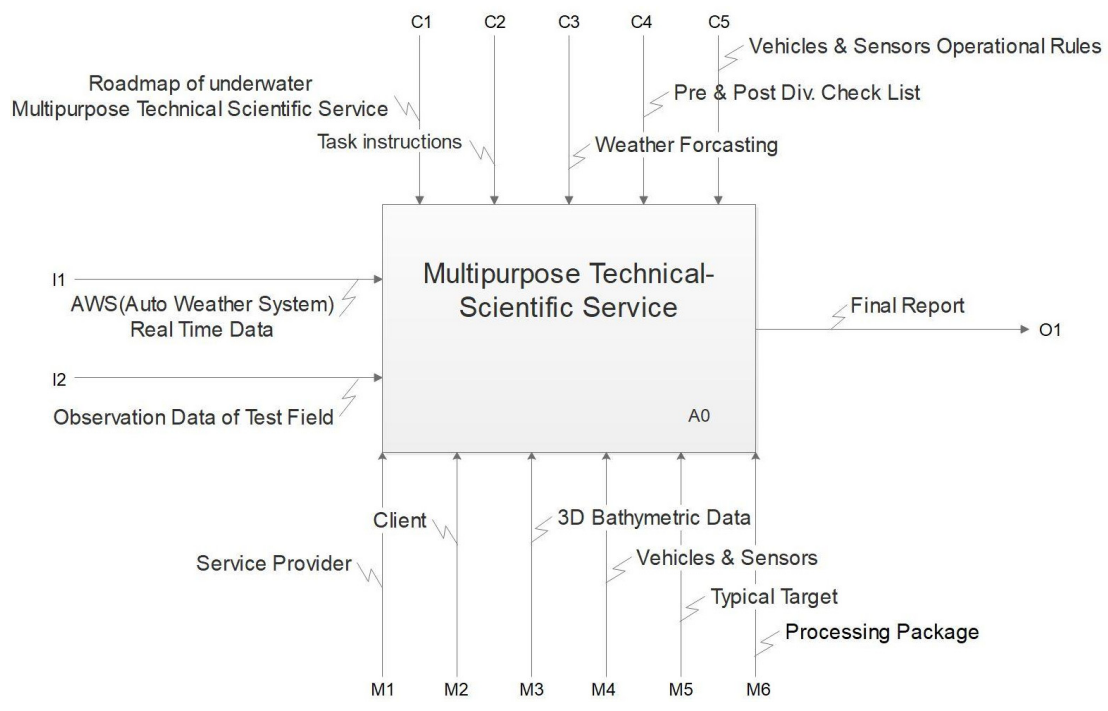

Fig. 11 A-0 diagram of multipurpose technical scientific service 


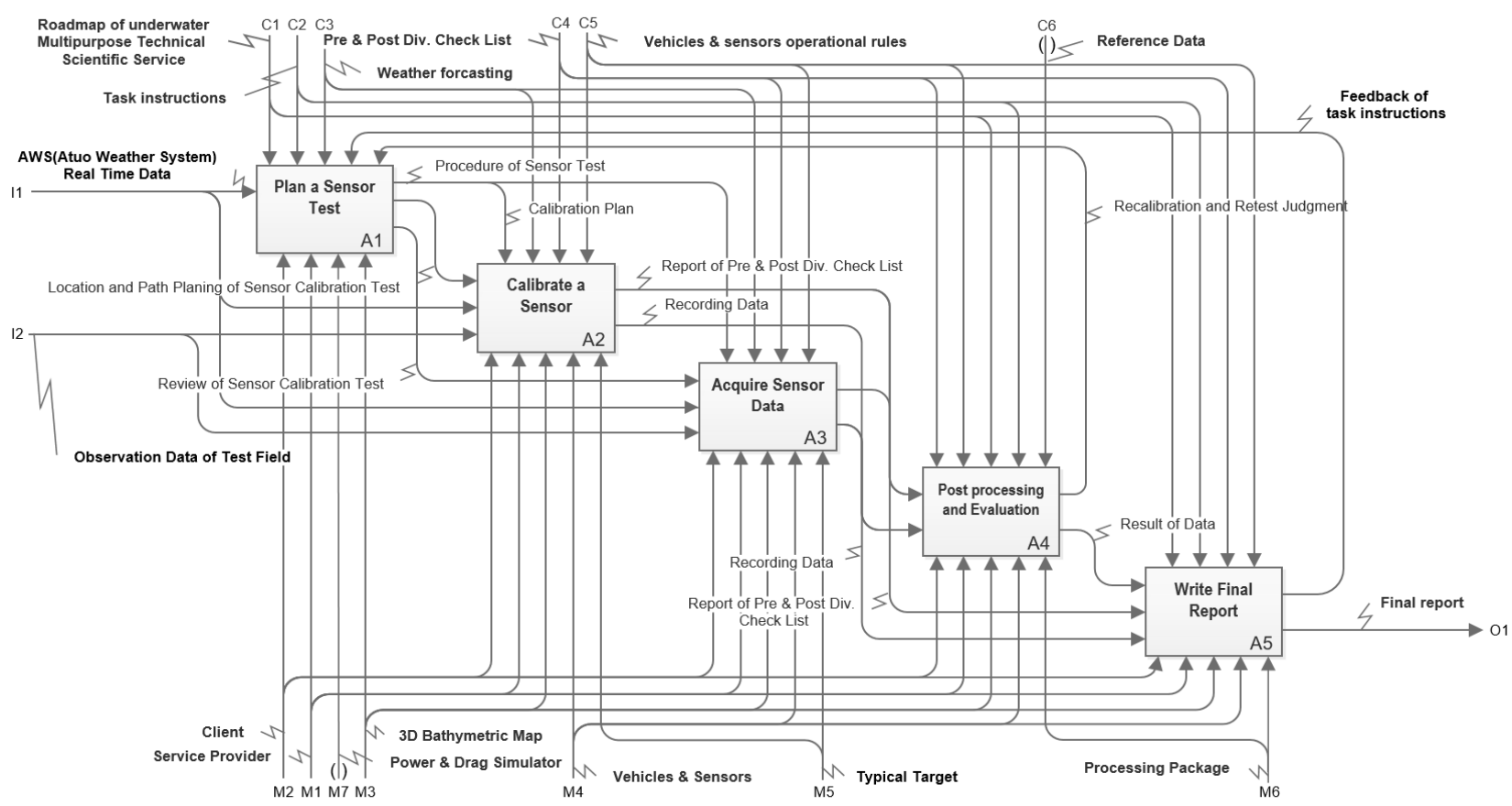

Fig. 12 A0 diagram subdivided from A-0 diagram

test-bed operation rules and roadmap, test request, weather forecast, pre- and post-diving check list for maritime equipment, and operation rules for equipment and sensors. Mechanism elements for acquiring data include wave power generation test-bed (service provider), customer, existing three-dimensional seabed terrain data, maritime equipment (vehicles and sensors) used in tests, fixed target structure, and processing software package. The next level down consists of five activities. A1 (sensor test plan), A2 (sensor calibration), A3 (sensor data acquisition), A4 (test data analysis and evaluation), and A5 (final report generation), as shown in Fig. 12. The activities are connected to each other by the ICOM flow and are expressed as a procedure.

In this section, an IDEF0 modeling method was selected to establish a standard procedure required to operate a variety of maritime equipment on an offshore wave power generation test-bed, and a draft of the procedure was established. As a result, it was found that data needed to be delivered to a user via a network in real time by installing underwater environment sensors and AWS in wave power plant facilities, and the shape and location information of artificial seabed structures and the topographic map of the seabed of neighboring sea prior to enforcement, need to be provided. It was also found that test-bed operation rules and roadmap were required. This study presents IDEF0 modeling results from the point of view of a person who acquires data. In future, research and development for integrated comprehensive real-sea experiment processes should be carried out from the point of view of a manager of the wave power test-bed.

\section{Suitability Analysis of Test Environment of Maritime Equipment}

Performance tests required for the development of autonomous underwater vehicles or remotely operated vehicles are often carried out in a large water basins, lakes, or gulfs. When a deep-sea environment is required, a research vessel (R/V) such as Onnuri (KIOST, 2019b) or Isabu (KIOST, 2019c) are used to perform tests on far seas such as the East Sea and the Pacific Ocean. This section analyzes the characteristics of the wave power test-bed and existing cases and identify fields in which OWC facilities are expected to be used.

\subsection{Differences from Existing Domestic Cases}

A variety of maritime equipment and robots are being developed in South Korea. ASVs, AUVs, and ROVs are being developed, and related application technologies are being actively studied. Tests for performance verification in the development process of such platforms and technologies are necessary, and support vessels or facilities of various types are also required.

The KRISO has carried out performance tests on ISiMI 100 (AUV) (Jun et al., 2009), ISiMI 6000 (Lee et al., 2012), Hemire (ROV), and Crabster (ROV) at the SSRI in the aid of various research vessels. Up to two individuals worked to test the relatively small ISiMI 100 weighing approximately $20 \mathrm{~kg}$ in the air by using a small fishing boat (Fig. 13). The ISiMI 6000 (AUV) weighing $750 \mathrm{~kg}$ in the air and the Hemire (ROV) weighing $4 \mathrm{t}$ were launched and recovered by using a crane installed at the wharf (Fig. 14). In such cases, the launch/
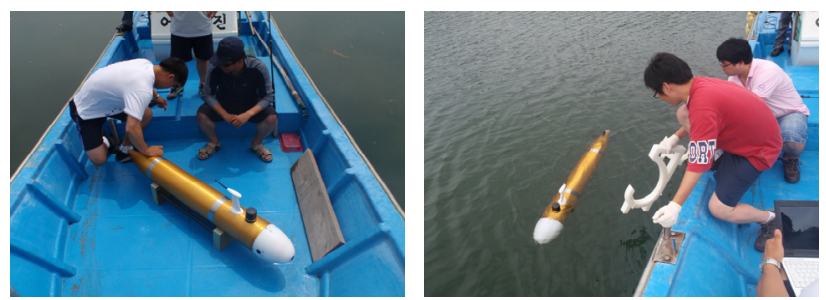

Fig. 13 ISiMI 100 AUV experiments using a small boat 

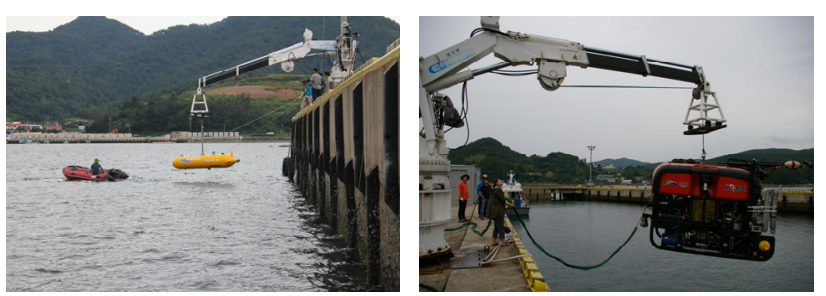

Fig. 14 Launch and recovery of ISiMI 6000 AUV and Hemire ROV using a crane in a port

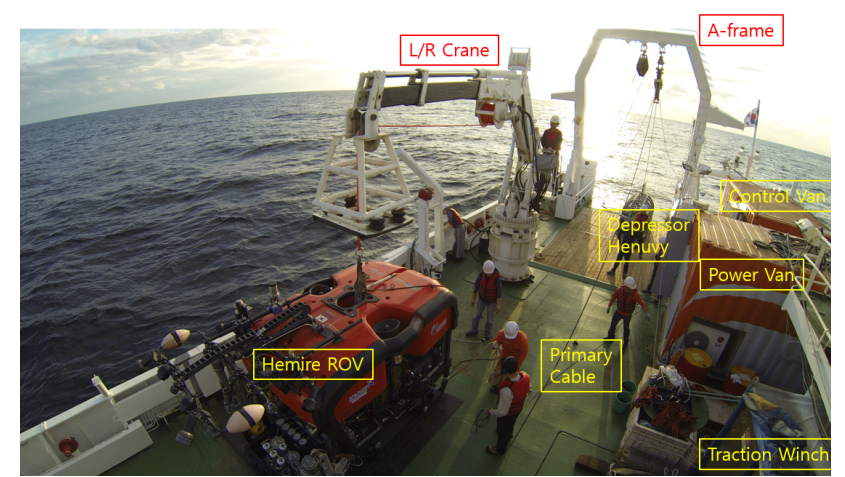

Fig. 15 Hemire ROV system on Onnuri R/V (Baek et al., 2012)

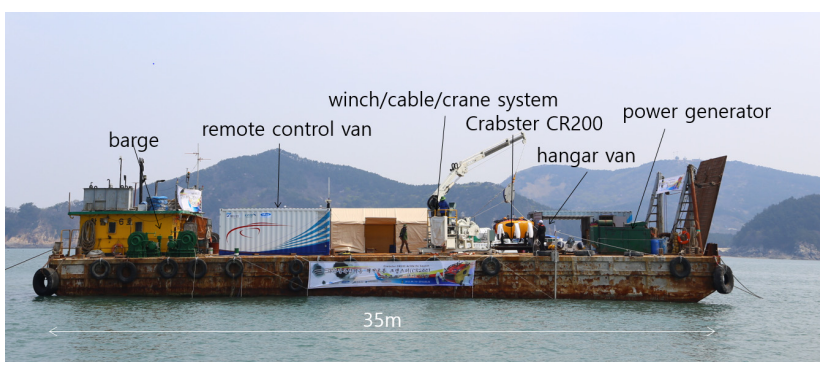

Fig. 16 Crabster ROV system on the barge (Jun et al., 2015a; Jun et al., 2015b)

recovery space is limited to the operating radius of the crane. In addition, an office space was constructed using a container for the research activities of test participants, and was used to analyze the data of the vehicles or change and modify the platform.

When tests on far seas such as the East Sea and the Pacific Ocean were required, research vessels such as Onnuri were used (Lee et al., 2016) (Fig. 15). When testing Crabster (walking ROV), a barge was used (Jun et al., 2017) (Fig. 16). The wave power test-bed is bound to be different from such research vessels and wharf environments.

\subsection{Characteristics of Wave Power Test-bed}

Qualitatively, the test-bed sea is between the environment of a lake or gulf, and the real-sea environment of the East Sea and the ocean. It takes approximately 40 minutes from the Hallim port and an hour and ten minutes from the Aewol port each way, travelling by a Jangmok No. 1-class vessel. Scheduled marine operation and the presence of other vessels must be checked before entering the test sea. Moreover, although marine traffic is light, it must be investigated in advance as it can change according to season and quantum of fish caught.

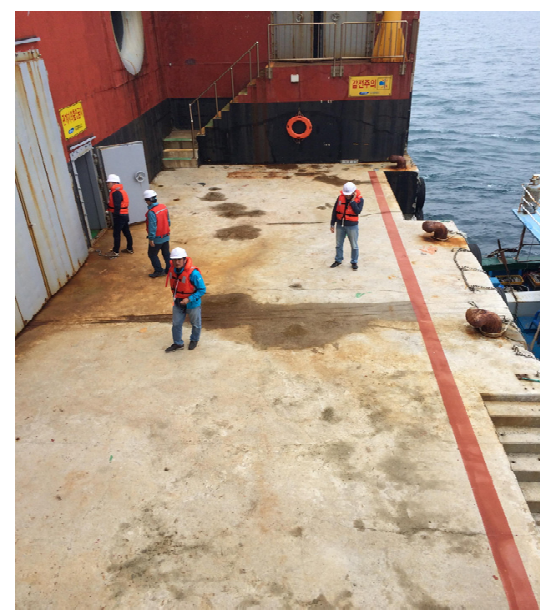

Fig. 17 Deck space of the OWC

Table 3 General conditions and preference levels for marine equipment test-sites

\begin{tabular}{|c|c|c|c|c|c|}
\hline & \multirow{2}{*}{ Item } & \multicolumn{2}{|c|}{ Offshore } & \multicolumn{2}{|c|}{ Onshore } \\
\hline & & OWC & $\mathrm{R} / \mathrm{V}$ & Port & Seashore \\
\hline \multirow{5}{*}{ Operation } & Op. 1 & 3 & 5 & 5 & 4 \\
\hline & Op. 2 & 5 & 5 & 5 & 2 \\
\hline & Op. 3 & 5 & 5 & 5 & 2 \\
\hline & Op. 4 & 3 & 4 & 5 & 3 \\
\hline & Op. 5 & 3 & 4 & 5 & 2 \\
\hline \multirow{4}{*}{ Support } & Sp. 1 & 4 & 3 & 4 & 2 \\
\hline & Sp. 2 & 3 & 4 & 3 & 2 \\
\hline & Sp. 3 & 3 & 3 & 5 & 4 \\
\hline & Sp. 4 & 3 & 3 & 5 & 3 \\
\hline Item & \multicolumn{5}{|c|}{ Description } \\
\hline Op. 1 & \multicolumn{5}{|c|}{$\begin{array}{l}\text { 1. Operator support facility } \\
\text { - 24hours operation (Kitchen \& bads) } \\
\text { - 12hours operation (Day work) }\end{array}$} \\
\hline Op. 2 & \multicolumn{5}{|c|}{$\begin{array}{l}\text { 2. Power \& communication } \\
\text { - Electricity from ground } \\
\text { - Wired \& wireless communication }\end{array}$} \\
\hline Op. 3 & \multicolumn{5}{|c|}{$\begin{array}{l}\text { 3. CCTV \& surveillance } \\
\text { - Monitoring for operation and sea state } \\
\text { - Surveillance for warehouse and facility }\end{array}$} \\
\hline Op. 4 & \multicolumn{5}{|c|}{$\begin{array}{l}\text { 4. Washing and maintenance } \\
\text { - Fresh water } \\
\text { - Space for maintenance }\end{array}$} \\
\hline Op. 5 & \multicolumn{5}{|c|}{$\begin{array}{l}\text { 5. Launch and recovery system } \\
\text { - Crane, A-Frame, J-Frame } \\
\text { - Peripheral devices such like power generators }\end{array}$} \\
\hline
\end{tabular}

Sp. 1 6. Berth of support vessels

- Barge, boat, etc

Sp. 2 7. Mobility of support vessels

8. Accessibility

Sp. 3 - Sea state

- Installation \& disassemble

9. Accessibility to land resources

Sp. 4 - Repair and replacement

- Manufacturing such like milling or drilling 5: Best, 4: Good, 3: Average, 2: Bad, 1: Worst 
The OWC can supply electricity and relay communication. If real-time kinematic (RTK) GPS is installed, it can be used as a location reference point. If a long-range (LoRa) low-power wide-area network is installed, it can supply a wireless communication network up to a range of approximately $10 \mathrm{~km}$. If a network camera illuminates the surroundings, it is expected that the weather and sea state can be checked in real time from a remote location to make a more suitable test plan. A space that can be used as a deck is provided on the outside (Fig. 17), and a space for maintenance, repair, and storage of equipment as well as office work is provided on the inside. The water depth ranges from $10 \mathrm{~m}$ to $60 \mathrm{~m}$. The laid cables can be used as a landmark. The wave power energy density is relatively high as the wave power test-bed is installed at this location.

It is comparable to Onnuri-class research vessels in supplying power, relaying communication, and monitoring sea state. However, research vessels are equipped with room and board facilities, whereas the wave power test-bed is not. Moreover, research vessels have various support devices for launch and recovery, whereas the wave power test-bed is still in preparation for construction. The advantages and disadvantages of offshore and land test-beds from an operational and support facility perspective are listed in Table 3.

Table 3 is divided into an operation area and a support area. The operation area is divided into five sub-items and the support area is divided into four sub-items. Locations to be compared include a research vessel $(\mathrm{R} / \mathrm{V})$, port, and seashore. Furthermore, the convenience of each item according to a comparative location is quantified. A score of 5 points means best, and a score of 1 means worst. The quantifying process is heuristically derived based on the experience of the authors, and the advantages and disadvantages of facilities may be changed depending on the target to be tested.

Op. 1 refers to operator support facilities, which denotes the ability to provide room and board in a $24 \mathrm{~h}$ operation or daytime work convenience in a $12 \mathrm{~h}$ operation. The $\mathrm{R} / \mathrm{V}$ and port are preferred, and the OWC is average. This is because it is not yet equipped with facilities for room and board, kitchen, and bathroom. Op. 2 is items related to power and communication. If power can be supplied from land/ground, the system utilization can be improved in most cases. The communication network can also better acquire related information and analyze data with the aid of wired/wireless internet and long-term evolution (LTE) mobile data. Accordingly, the OWC can provide a very favorable environment. Op. 3 relates to closed-circuit television (CCTV) installation and security (CCTV \& surveillance). A CCTV has security elements (e.g., intruder identification) and can provide a function for observing large research equipment from multiple angles while it is being driven. Numerous CCTVs can be installed on the OWC. Op. 4 relates to washing and maintenance space for test equipment. The OWC can provide a good environment in Op. 3 and Op. 4. Op. 5 is the launch and recovery system for equipment. The equipment can enter the sea directly from the OWC, but support facilities for launching and recovering heavy equipment still need to be procured. Sp. 1 relates to ease of berthing support vessels. The OWC and port are better in Sp. 1. Sp. 2 relates to mobility of support vessels and recovery support when equipment is lost. The immediately movable research vessel is favored, and the OWC is not. Sp. 3 is accessibility to the test sea and includes the ease with which test participants enter and withdraw as sea states such as rain and wave height change. Sp. 4 is accessibility to land resources and relates to unexpected faults of equipment, manufacturers or repair companies, and how easily replacements can be purchased. The port is favored highly, and the OWC is average.

\subsection{Applicable Fields/Businesses}

The fields expected to make use of the facilities described in this paper were identified as follows.

(1) Wave energy-based mobile unmanned system test evaluation

This relates to performance tests and evaluation for mobile wave power generation systems, or marine mobile unmanned systems using wave energy. It can be used as a berth facility for launch and recovery of unmanned vehicles and can be used as an integrated control center for monitoring, remotely controlling, and tracking the location of an unmanned vehicle.

(2) Construction of a wave power test-bed using a wave glider and long-term surrounding environment monitoring system

This relates to construction of a continuous environment monitoring system using wave gliders that use wave energy to secure safety and predict the energy production of a wave power test-bed. The gliders can be used as a monitoring system for stable energy production prediction of the wave power test-bed, and the wave power test-bed can be used as an integrated control center of the wave gliders.

(3) Domestic maritime measurement sensor performance tests and evaluation

Various sensors are arranged on the wave power test-bed and can be used in preparation of a standard operation procedure and their performance verification. The power and communication provided by the wave power test-bed can be used to provide investigating entities with location correction and real-time environment information. It can be used in search performance evaluation activities such as navigation or underwater exploration missions using laid submarine cables as a landmark.

(4) Independent and group operation performance evaluation support system for marine unmanned vehicles

The wave power test-bed can operate as a control center of unmanned vehicles. If RTK GPS is installed in the future, it can operate as a location reference point and monitor each vehicle.

(5) Underwater communication network performance evaluation support system

Underwater communication technology is advancing beyond one-to-one communication to realize networks for three or more nodes. Performance test demands in the real sea are also expected to increase. The test-bed can be used as a single node, and a location reference point and can relay offshore and land communication. 


\section{Conclusions}

In this study, preliminary research was carried out on the suitability of OWC surroundings (Berth No. 1 of the wave power test-bed) to test the performance of maritime equipment. The authors boarded Jangmok No. 1 and accessed the sea of the wave power test-bed from the Hallim port and Aewol port for this study. While operating typical seabed mapping sensors, the multi-beam echo sounder and single-beam scanning sonar, the conditions that would be required when used as a test-bed of maritime equipment in the future were investigated, and the terrain information for the underwater lower structure of the wave power test-bed and the surrounding seabed environment was procured. The procured terrain information is expected to be used as reference data when investigating terrain changes in the future. In addition, the procedure required to use the facilities described in this paper was modeled using IDEF0 techniques. The modeling results provide a reference procedure for carrying out various complex and novel experiments in future, and are used to minimize technology duplication and risk. Feedback from additional experiments can correct and modify the model to develop a thorough standard procedure. Past cases were also analyzed, and the characteristics of the test-bed were derived based on the analysis. Finally, five fields expected to make use of the facilities were identified.

\section{Acknowledgments}

This research was supported by a grant from National R\&D Project "Establishment of sea test-bed for wave energy converters" funded by Ministry of Oceans and Fisheries, Korea (PMS4040) and was supported by a grant from Endowment Project of "Development of rated power control technology for OWC wave energy converter using flow control system" funded by KRISO (PRS0200).

\section{References}

Baek, H., Jun, B., Choi, G., \& Lee, P. (2012). A Case Study on the Operation Strategy of Hemire from the Analysis of Deep-Sea ROV Operations. Abstract book of The Korean Society for Marine Environment \& Energy, 1723-1729.

Baek, H., Jun, B.H., Yoon, S.M., \& Noh, M. (2019). Study on Identification Procedure for Unidentified Underwater Targets Using Small ROV Based on IDEF Method. Journal of Ocean Engineering and Technology, 33(3), 289-299. https://doi.org/ 10.26748/KSOE.2019.022

Baek, H., Kim, K.H., Jun, B.H., Lee, P.M., \& Lim, Y.K. (2008). Estimation of the Hydrodynamic Coefficients for the Deep-sea UUV. Journal of Ocean Engineering and Technology, 22(4), 97-105.

Choi, J., Park, J., Jung, J. \& Choi, H.T. (2019a). Development of Underwater 3D Positioning System using Underwater Acoustic
Modem. Journal of Institute of Control, Robotics and Systems 25(10), 916-922. https://doi.org/10.5302/J.ICROS.2019.19.0155

Choi, J.S., Lee, J.K., Lim, C.H., Ko, T.K., Park, J.Y., Kim, K., ... \& Cho, I.H., (2019b). Current State of Development of the Open Sea Test Site for Wave Energy Converters. Proceedings of The Joint Conference of the Korean Association of Ocean Science and Technology Societies 2019.

González, J., Monagas, V., Remírez, X., Luque, A., Hernández J., \& Llinás, O. (2015). PLOCAN. An Offshore Test Site for Ocean Energy Converters. Proceedings of OCEANS 2015 - Genova, Genoa, 1-4, https://doi.org/10.1109/OCEANS-Genova.2015. 7271245 .

Jeollabuk-do. (2019). Report of Feasibility Analysis Research of Establishment for Small Marine Unmanned System Demonstration Platform. Republic of Korea

Jun, B.H., Jeong, Y.H., Shim, H., \& Lee, P.M., (2015a). An Experiment on Searching, Identification and Recovery of Underwater Artefacts off the Western Coast of Korea Using Underwater Walking Robot Crabster CR200. Proceedings of the 2015 Spring conference of the Korean Society of Mechanical Engineers, $710-712$.

Jun, B.H., Lee, F.Y., Park, J.Y., Lee, P.M. \& Kim, S.M. (2009). Analysis of Control Responses in the Field Test of ISiMI100 AUV, Proceedings of the 2009 Fall conference of the Korean Society of Ocean Engineers, 12-16.

Jun, B.H., Lee, P.M., \& Jung, Y.H. (2015b). Experience on Underwater Artefact Search using Underwater Walking Robot Crabster CR200. Proceedings of OCEANS 2015 MTS/IEEE Washington, Washington, DC, 1-5, https://doi.org/10.23919/OCEANS.2015. 7404618 .

Jun, B.H., Yoo, S.Y., Lee, P.M., Park, J.Y., Shim, H., \& Baek, H. (2017). The Sea Trial of Deep-sea Crabster CR6000 System. IEMEK Journal of Embedded Systems and Applications, 12(5), 331-341. https://doi.org/10.14372/IEMEK.2017.12.5.331

Kim, C.W. (2005). A Study on the Information Modeling of Defense R\&D Process Using IDEF Methodology. The Journal of Society for e-Business Studies, 10(1), 41-60.

Kim, H., Kim, J., Cho, I.H., Paeng, D.G. \& Choi, J.S. (2017). Survey of Seafloor at Chagwi-do of Jeju Island to Select 60-m-class Sea Test Bed of Wave Energy Converter. Journal of Ocean Engineering and Technology, 31(4), 308-314. https://doi.org/ 10.26748/KSOE.2017.08.31.4.308

Korea Institute of Ocean Science \& Technology (KIOST). (2019a). R/V Jangmok No. 1. Retrieved from https://www.kiost.ac.kr/lab/ sub05_04.do

Korea Institute of Ocean Science \& Technology (KIOST). (2019b). R/V ONNURI. Retrieved from https://www.kiost.ac.kr/lab/sub05_02.do

Korea Institute of Ocean Science \& Technology (KIOST). (2019c). R/V ISABU. Retrieved from https://www.kiost.ac.kr/lab/sub05_01.do Lee, G.M., Park, J.Y., Lee, P.M., Jun, B.H., Kim, K.H., Lee, C.M., ... \& Jeong, H.S. (2012). Design of $6000 \mathrm{~m}$ Autonomous Underwater Vehicle ISiMI6000. Proceedings of The Joint Conference of the 
Korean Association of Ocean Science and Technology Societies 2012. 1719-1722.

Lee, P.Y., Park, S.K., Kwon, S.T., Park, S., Jung, H., Park, M.S., \& Lee, P.M. (2015). Dynamic Modeling of Autonomous Underwater Vehicle for Underwater Surveillance and Parameter Tuning with Experiments. Journal of Ocean Engineering and Technology, 29(6), 488-498. https://doi.org/10.5574/KSOE.2015.29.6.488

Lee. P.M., Jun, B.H., Baek, H., Kim, B., Shim, H., Park, J.Y., ... \& Kim, W.S., (2016). Explorations of Hydrothermal Vents in Southern Mariana Arc Submarine Volcanoes using ROV Hemire. Journal of Ocean Engineering and Technology, 30(5), 389-399. https://doi.org/10.5574/KSOE.2016.30.5.389

Park, J.Y., Ko, T.K., Choi, J.S., Kim, K.H., Lee, J.K., Kim, G.W., ... \& Baek, W.D. (2019). Establishment of Wave Energy Data for Performance Assessment of Wave Energy Converter. Proceedings of the 2019 Fall Conference of the Korean Society for Marine Environment and Energy, 79-84.

Park, S.K., Lee, P.Y., Park, S.W., Jung, H.S., \& Park, M.S. (2015). Design and Field Test of Heading and Depth Control for Autonomous Underwater Vehicle HW200. Proceedings of Institute of Control, Robotics and System Annual Conference. 365-366.

Plataforma Oceánica de Canarias (PLOCAN). (2020). Oceanic Offshore Platform. Retrieved from https://www.plocan.eu/ en/offshore-platform

Real-Arce, D.A., Barrera, C., Hernández, J., \& Llinás, O. (2015). Ocean
Surface Vehicles for Maritime Security Applications (The PERSEUS Project). Proceedings of OCEANS 2015 - Genova, Genoa, 1-4. https://doi.org/10.1109/OCEANS-Genova.2015. 7271504 .

Rocha, F., \& De Tomi, G. (2015). Basic Mapping of the Inspection Process in Offshore Oil Production Facilities. Proceedings of OCEANS 2015 MTS/IEEE, Washington, 1-8. https://doi.org/ 10.23919/OCEANS.2015.7404581

Ryu, H.J., Hong, K., Shin, S.H., Kim, S.H., \& Kim, Y.D. (2011). Study on Analysis of Wave Energy Resources and Wave Energy Density Map of the Korean Sea Area. Proceedings of Joint Meeting of the Korean Association of Ocean Science and Technology, 1464-1468.

The National Institute of Standards and Technology. (1993). Draft Federal Information Processing Standards Publication 183. U.S. Department of Commerce(Springfield), Virginia.

\section{Author ORCIDs}

$\begin{array}{ll}\text { Author name } & \text { ORCID } \\ \text { Park, Jin-Yeong } & 0000-0002-8255-6402 \\ \text { Baek, Hyuk } & 0000-0002-3371-4160 \\ \text { Shim, Hyungwon } & 0000-0002-7314-2881 \\ \text { Choi, Jong-Su } & 0000-0003-4904-8390\end{array}$

